Marquette University

e-Publications@Marquette

Electrical and Computer Engineering Faculty

Electrical and Computer Engineering, Department

Research and Publications

3-20-2018

\title{
Foreword: Special Section on Electrical Contacts
}

Ronald A. Coutu Jr.

Marquette University, ronald.coutu@marquette.edu

Ravi Mahajan

Intel Corporation

Accepted version. IEEE Transactions on Components, Packaging and Manufacturing Technology, Vol. 8, No. 3, (March 2018): 331-332. DOI. (C) 2018 IEEE. Used with permission. 
Marquette University

\title{
e-Publications@Marquette
}

\section{Electrical and Computer Engineering Faculty Research and Publications/College of Engineering}

This paper is NOT THE PUBLISHED VERSION; but the author's final, peer-reviewed manuscript.

The published version may be accessed by following the link in the citation below.

IEEE Transactions on Components, Packaging and Manufacturing Technology, Vol. 8, No. 3 (March, 2018). DOI. This article is (C) Institute of Electrical and Electronic Engineers (IEEE) and permission has been granted for this version to appear in e-Publications@Marquette. Institute of Electrical and Electronic Engineers (IEEE) does not grant permission for this article to be further copied/distributed or hosted elsewhere without the express permission from Institute of Electrical and Electronic Engineers (IEEE).

\section{Foreword: Special Section on Electrical Contacts}

\author{
Ronald A. Coutu \\ Marquette University, Milwaukee, WI \\ Ravi Mahajan \\ Intel Corporation, Chandler, AZ
}

\begin{abstract}
:
Welcome to the Special Topics Section dedicated to the 2016 Holm Conference on Electrical Contacts. This Special Section contains six high-quality papers that comprehensively describe the state of the art and potential future directions for topics of great interest to our readers. The Editor-in-Chief (EIC), in consultation with the other EICs, Associate Editors (AEs), and domain experts, selects the topics for the Special Sections, and a Guest Editor or AE (GE/AE), who is a leading expert in the technical area, and
\end{abstract}


then directs the solicitation and peer review of the papers. In cases where the GE/AE is also an author, the EIC is responsible for the peer review to avoid any real or perceived conflicts of interest.

Welcome to the Special Topics Section dedicated to the 2016 Holm Conference on Electrical Contacts. This Special Section contains six high-quality papers that comprehensively describe the state of the art and potential future directions for topics of great interest to our readers. The Editor-in-Chief (EIC), in consultation with the other EICs, Associate Editors (AEs), and domain experts, selects the topics for the Special Sections, and a Guest Editor or AE (GE/AE), who is a leading expert in the technical area, and then directs the solicitation and peer review of the papers. In cases where the GE/AE is also an author, the EIC is responsible for the peer review to avoid any real or perceived conflicts of interest.

This Special Topics Section focuses on new and emerging technologies in the electrical contacts area including advanced modeling, promising new contact materials, microcontacts and microelectromechanical systems (MEMS) switches, and improved direct-current (dc) circuit breaker topologies needed for electric vehicles and high-voltage solar applications.

The paper "Investigation on the Thermal Failure of Micro-USB Connectors in Mobile Phones" studies the frequently observed failure mechanism of burning around the micro-USB connectors that are used in products such as smartphones, tablets, and e-book readers.

The paper "Experimental Study on Contact Behavior of Tilted Contact in Air Circuit Breaker" investigates the contact behavior of tilted contacts found in air circuit breakers using a newly designed test apparatus.

The paper "Arcless Commutation of a Hybrid DC Breaker by Contact Voltage of Molten Metal Bridge" evaluates using the molten metal bridge phenomena to provide arcless commutation and interruption of dc current.

The paper "Electrical Lifespan Prediction of HVDC Relay Based on the Accumulated Arc Erosion Mass" predicts high-voltage dc relay lifetimes based on arc erosion mass derived using measured arc waveforms.

The paper "Simulation Methodology for Prediction of the Wear on Silver-Coated Electrical Contacts With a Sphere/Flat Configuration" uses Archard's wear equation, surface roughness, and contact geometry to predict the wear through of silver-coated electrical contacts.

The paper "Influences of Contact Opening Speeds up to $200 \mathrm{~mm} / \mathrm{s}$ and External Magnetic Field Application on Break Arc Duration Characteristics of $\mathrm{AgSnO}_{2}$ Contacts in dc $14 \mathrm{~V}$ Load Conditions up to Around $10 \mathrm{~A}$ " evaluates various break operations and their effects on silver-tin oxide electrical contacts under dc and inductive circuits loads.

We acknowledge all the authors who contributed papers and all the reviewers for their thorough reviews. We hope that this issue will serve as a valuable resource for the research community, as well as a catalyst for increased research and exploration in the exciting and far-reaching fields of electrical contacts. 